\title{
АРХИТЕКТУРНО-АРХЕОЛОГИЧЕСКИЙ КОМПЛЕКС АКЫРТАС
}

\author{
(C) 2018 г. К.М. Байпаков
}

\begin{abstract}
Акыртас - недостроенное сооружение из каменных блоков железистого песчаника. На территории памятника хорошо читаются две улицы: одна из них, направлением север-юг, - сквозная, другая, направлением восток-запад, - тупиковая, упирается в глухие айваны. Относительно комплекса Акыртас есть разные мнения: строился как буддийский или несторианский монастырь, караван-сарай или дворецрезиденция. По аналогии планировки, характеру строительной техники некоторые исследователи считают Акыртас дворцом, сооруженным арабскими зодчими в VIII в. Археологические материалы, полученные автором, позволяют датировать начало строительства временем после Атлахской битвы 751 г.

Ключевые слова: археология, Великий Шелковый путь, Акыртас, Касрибас, карлуки, арабы, Арабский Халифат, Кутейба, Атлахская битва, дворец, каменные блоки, карьер добычи камня
\end{abstract}

Введение. Акыртас - один из наиболее загадочных памятников на территории Таласской долины Казахстана (рис. 1-6). Он находится на трассе Великого Шелкового пути, на участке Чанань-Тянь-Шаньского коридора. Существуют мнения, что остатки этого грандиозного недостроенного каменного сооружения могут быть военной крепостью, несторианским монастырем, караван-сараем, дворцом. В статье рассматриваются эти предположения и предлагается авторское решение данного вопроса.

Описание памятника. Комплекс находится в 40 км восточнее города Тараза, в 6 км южнее ж/д ст. Акчулак, у подножия северных склонов Кыргызского Алатау. Комплекс расположен на старой караванной дороге - Тянь-Шаньском участке Великого Шелкового пути. Современная автомобильная трасса проходит севернее, это автобан Западный Китай - Западная Европа.

Комплекс памятников, относящихся к разным хронологическим периодам, состоит из могильника, насчитывающего пять сакских или усуньских курганов V-III вв. до н.э., остатков недостроенной постройки из каменных блоков. К комплексу относятся караван-сарай VIII-X вв. и караван-сарай X - начала XIII в., расположенные в 1 км юго-восточнее дворца. В 50 м от каменной постройки расположены остатки каравансарая XIII-XIV вв. и примыкающая к нему застройка. Прослежена система водоснабжения: два водохранилища и разветвленная система водопроводов из глиняных труб, которые берут начало в родниковых ущельях Узунбулак и Сасузек.

В 200-250 м юго-восточнее постройки из камня на восточном скло- 
Байпаков К.M. Архитектурно-археологический комплекс Акыртас

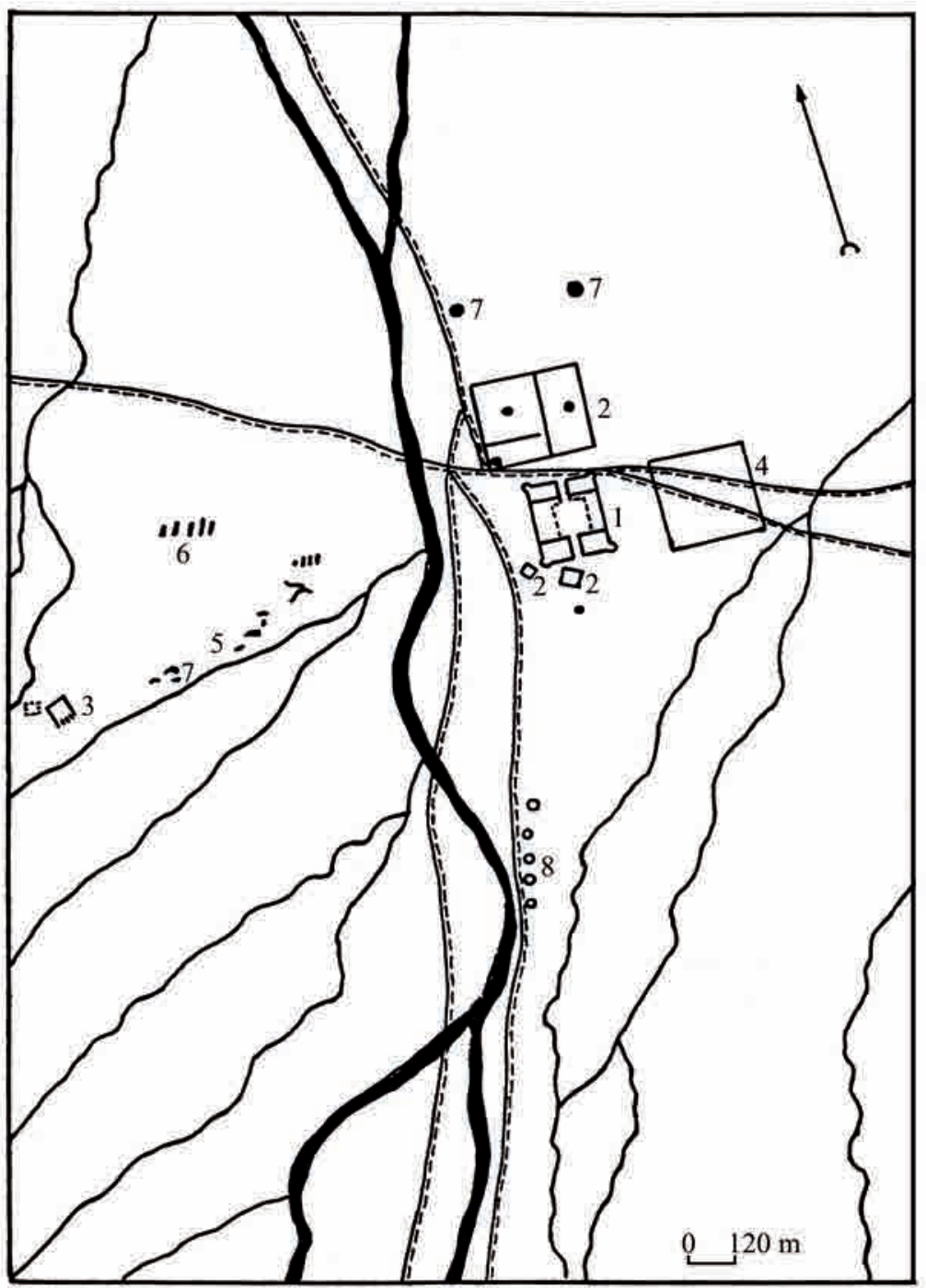

Рис. 1. Комплекс Акыртас. Ситуационный план. 1 - двориовый комплекс; 2 -жилые постройки; 3 - крепость (рядом с ней замок правителя); 4 - садово-парковая зона;

5 - каменоломня; 6 - глиняные карьеры; 7 - водохранилища; 8 - древние курганы

Fig. 1. Complex Akyrtas. Situational plan. 1 - palace complex; 2 - residential buildings; 3 -fortress (next to it is the castle of the ruler); 4 -landscape gardening area; 5 -quarry; 6 -clay pits; 7 - reservoirs; 8 - ancient burial mounds

не горы Кызылтас находятся карьеры по добыче камня - красного песчаника для постройки дворца и группа карьеров - выше по склону ущелья Узунбулак. На северном склоне горы Кызылтас обнаружены остатки карьера, где добывали глину для изготовления жженых кирпичей. На самой восточной точке горы Кызылтас обнаружены остатки караульной башни, сложенной из камня.

Двореи. Центром комплекса Акыртас является незавершенная постройка из красных каменных блоков. Комплекс привлекает внимание своей монументальностью, четким прямоугольным планом и мощными крепостными стенами с круглыми башнями 
по углам, а также красным цветом каменных блоков, выделяющихся на фоне весенней зелени или желтой выгоревшей травы летом и осенью.

Не случайно, еще в начале XIII в. на Акыртас обратил внимание даосский монах Чань-Чунь. Он принадлежал к «Северной даосской школе ордена Золотой лотос». Его адепты занимались поисками в духовном мире «философского камня» и средства обретения бессмертия. Легенда о том, что даосам известны секреты бессмертия, была популярна в самом Китае и за его пределами. Поэтому Чингисхан пригласил Чань-Чуня к себе в ставку в завоеванных землях.

В сопровождении военного экскорта монголов и в обществе 19 своих учеников осенью 1220 г. Чань-Чунь отправился в путь и прибыл в сентябре 1222 г. в ставку Чингисхана в Бадахшане. Он несколько раз встречался с Чингисханом. Наконец, 11 апреля Чань-Чунь отправился в обратный путь. На долгом пути один из его учеников по имени Ли Чицянь вел днев- ник и отмечал события, описывал местность и достопримечательности, а также записывал все слова учителя.

В дневнике есть следущая запись: «18 числа девятого месяца (3 ноября) мы тронулись вдоль подножья гор на запад, после семи или восьми дней путешествия хребты гор неожиданно повернули на юг. Открылся город, весь выстроенный из красных камней, там виднелись следы древнего военного лагеря. К западу были большие могильные насыпи, которые [расположением] напоминали Доусинь (созвездие большой Медведицы). Проехав через каменный мост и пропутешествов 5 дней вдоль юго-западных гор, мы въехали в город Сайлань» [Акишев А., 2004]. Нет сомнений: это описание именно Акыртаса, что подтверждается двумя сохранившимися до сих пор топонимами - названиями могильника Жетытобе (семь бугров) и Сайлань (город Сайрам).

Первые археологические раскопки сооружения Акыртас проведе-

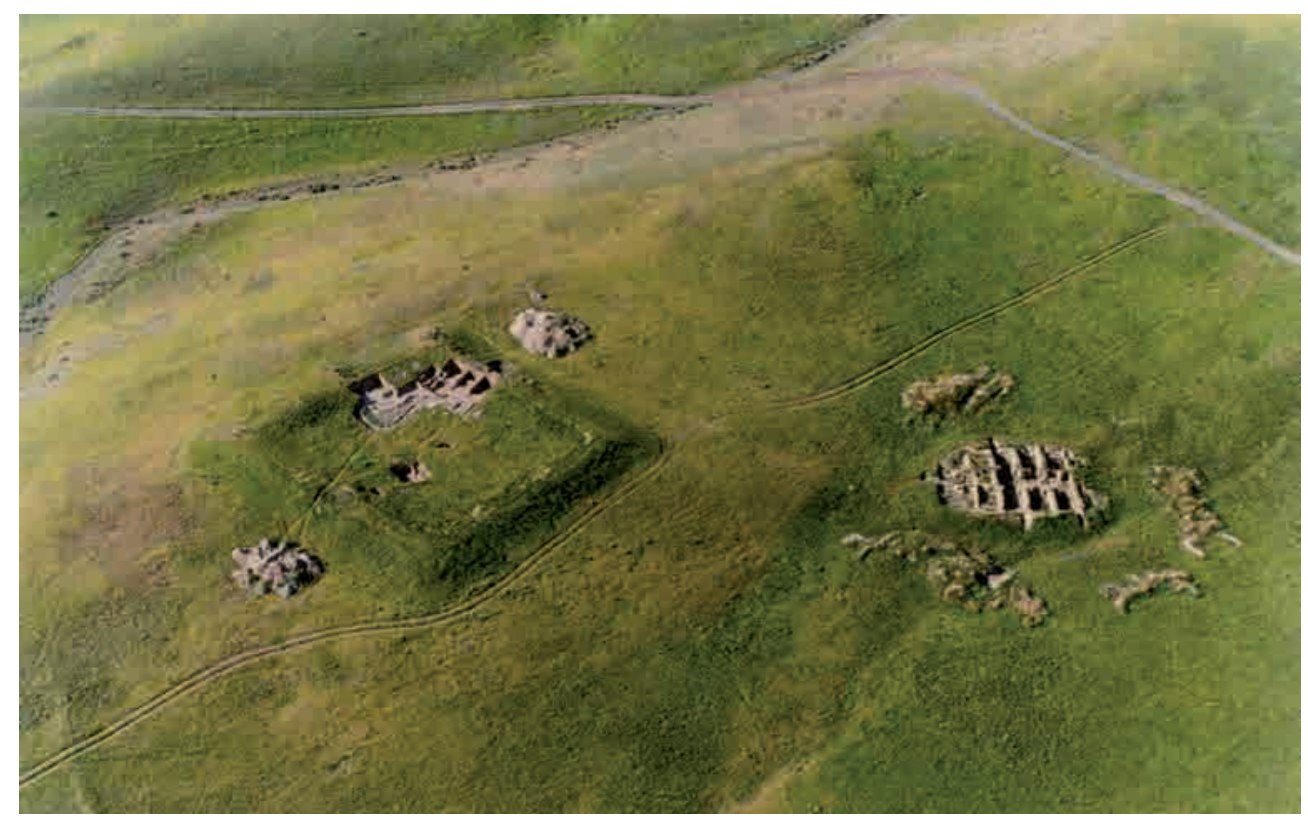

Рис. 2. Акыртас. Караван-сараи. Аэрофото. Фото автора

Fig. 2. Akyrtas. Caravanserai. Aero photo. Author's photo 
Байпаков К.M. Архитектурно-археологический комплекс Акыртас

ны в 1996 г. международной казахскофранцузской экспедицией на средства, выделенные акимом Жамбылской области А. Тшановым. Возглавляли экспедицию профессор Университета Сорбонны А. Нортхедж и директор Института археологии им. А.Х. Маргулана НАН РК, д.и.н. К.М. Байпаков. Затем, в 2004-2009 гг. и в 2015 г. на территории комплекса проводились археологические исследования по президентской программе «Мәдени мұра» (Культурное наследие). В 2014 г. этот уникальный памятник был включен в список Всемирного культурного наследия ЮНЕСКО [Байпаков, 2012, с. 245-255; Baipakov, 2016; Шарденова, 2010].

Внимание же к Акыртасу проявили уже первые российские исследователи, путешественники, а затем краеведы, ученые СССР и Республики Казахстан. История изучения выдающегося памятника культурного и сакрального наследия насчитывает более 160 лет. Первым, кто обратил внимание на него, был русский художник М.С. Знаменский, который в составе военной экспедиции генерала М.Г. Черняева в 1864 г. осмотрел развалины и сделал зарисовки панорамы Акыртаса и фрагментов его стен [Ивлев, 1989].

В 1867 г. Акыртас обследовал известный ориенталист П.И. Лерх. Он описал памятник, сделал замеры отдельных блоков и привел сведения о развалинах, упоминаемые Чан-Чунем. Вначале исследователь считал Акыртас буддийским монастырем [Лерх, 1870, с. 28-29, 34-39]. Несколькими годами позже серьезные исследования провел здесь геолог Д.Л. Иванов, в статье которого об Акыртасе имеется подробное описание плана сооружения и каменоломни, откуда брались камни для строительства. Он же дал характеристику стеновых блоков и сделал зарисовки тех из них, которые были орнаментированы [Иванов, 1886, с. 162-167].

В 1890-е гг. Акыртас вновь привлекает к себе внимание. Так, в 1893 г. его посещает известный востоковед В.В. Бартольд. Он приводит легенду о памятнике, распространенную среди местного населения, и интерпретирует его как монастырь христиан-несторианцев. Такая гипотеза стала возможной благодаря рассказам некоторых очевидцев, якобы видевших каменный блок из Акыртаса с изображением рыбы - одним из символов христианства [Бартольд, 1996, с. 37-39].

Член Туркестанского кружка любителей археологии, начальник Аулиеатинского уезда В.А. Каллаур, исследуя Акыртас, обнаружил водопроводные трубы и каменные желоба и пришел к выводу, что вода подводилась к постройке из родников, расположенных в 4-5 км выше - в горных ущельях [Каллаур, 1896, с. 25-27; 1905 , c. 29-36].

Для отождествления Акыртаса с конкретным населенным пунктом В.А. Каллаур обратился к письменным источникам Ибн Хордадбеха и Кудамы. Именно они приводят в своих дорожниках наиболее подробный реестр городов на участке торгового пути от Тараза до Кулана. Это Нижний Барсхан в 3 фарсахах от Тараза, затем через 2 фарсаха Касри-бас (Касрибас), далее в 2 фарсахах КульШуб, затем в 4 фарсахах Джуль-Шуб, затем Кулан, до которого был путь длиной в 4 фарсаха [Волин, 1960, с. 73-74, 76-77; Каллаур, 1897, с. 1-9]. В.А. Каллаур отождествлял Акыртас с Касрибасом и считал его несторианской постройкой [Каллаур, 1897, c. 1-9].

B.B. Бартольд сопоставлял Касрибас с тюркской крепостью Качар-баши, дважды упоминаемой в Шахнаме, и помещал ее на месте Аулие-Ата (Тараза) [Бартольд, 1964, 
c. 281-282]. В советское время интерес к Акыртасу не пропадал, в частности, он оказался в поле зрения работ Семиреченской археологической экспедиции (1936-1938 гг.), возглавляемой А.Н. Бернштамом. Считая Акыртас несторианской постройкой, A.Н. Бернштам датировал его XIIXIV вв. [Бернштам, 1949, с. 121].

В 1940, в 1945-1946 гг. Акыртас исследовал Г.И. Пацевич, который в это время возглавлял Джамбулский археологический пункт. Он посвятил памятнику статью, в которой характеризует топографию Акыртаса, приводит описание помещений, дво$\mathrm{pa}$, оснований колонн во дворе. Он же описывает карьеры, где ломали камни, пишет о водоснабжении. По мнению Г.И. Пацевича, Акыртас датируется временем до IX в. и, скорее всего, является постройкой христианнесторианцев. Он также согласился с мнением о тождестве Акыртаса с Касрибасом, расположенным на трассе Великого Шелкового пути [Пацевич, 1949, с. 80-85]. Затем Акыртас исследует экспедиция отдела архитектуры при Совете Министров КазССР. Материалы исследований были обобщены в статье архитектора Т.К. Басенова. Он отвергает попытки считать Акыртас буддийским либо несторианским монастырем и предполагает, что Акыртас - дворец-крепость, построенный в VIII-IX вв. [Басенов, 1950, с. 83-89]. Л.Ю. Маньковская, проанализировав план постройки, пришла к выводу, что Акыртас представляет собой недостроенный караван-сарай с центральным двором и малыми дворами разного назначения. По ее мнению, он строился как торговый центр - перевалочный пункт на торговом пути. Исследователь датирует начало строительства не позже X в. и присоединяется к мнению о тождестве Акыртаса и Касрибаса [Маньковская, 1980, c. 65-67].
И, наконец, еще одна попытка объяснения назначения Акыртаса предпринята была немецким исследователем Б. Брентьесом. Он полагает, что Акыртас строился по приказу арабского полководца Кутейбы и называет дату начала строительства - 714-715 гг., когда Кутейба ибн Муслим стал правителем Центральной Азии и перешел в оппозицию центральной власти халифата. Опасаясь за свою судьбу и своей семьи, он вызвал ее к себе. Семья добралась до Мерва, когда Кутейба был уже убит [Brentjes, 1993].

Б. Брентьес отметил сходство архитектуры Акыртаса и ранних монументальных построек Халифата. По его заключению здания, подобные Акыртасу в Казахстане, в Средней Азии неизвестны, а его ближайшая аналогия - дворец Каср аль-Хайр аль-Шарки (Каср аль-Хайр восточный), сооруженный в 728-729 гг., находится в 97 км к северо-востоку от Пальмиры. Характерный принцип планировки зданий - общий для обоих значительно отдаленных один от другого. Он состоит в том, что по сторонам внутреннего двора расположены отдельные «дома», в состав которых входят замкнутые группы помещений, объединенных внутренним двориком и особыми функциями. В омейядском дворце этих групп 12: по 4 на каждой стороне квадратного, слегка перекошенного плана, 7 «домов»- однотипные жилые комплексы с внутренними двориками, окруженными аркадами. Один «дом» состоит из хозяйственных помещений и складов, еще один - в юго-восточном углу — мечеть классического арабского типа, «дома» в остальных трёх углах - это разделенные пополам дворы.

Этот же прием планировки лег в основу крупных дворцовых комплексов аббасидского времени - таких, как Охейдир (вторая половина VIII в.) 
Байпаков К.M. Архитектурно-археологический комплекс Акыртас

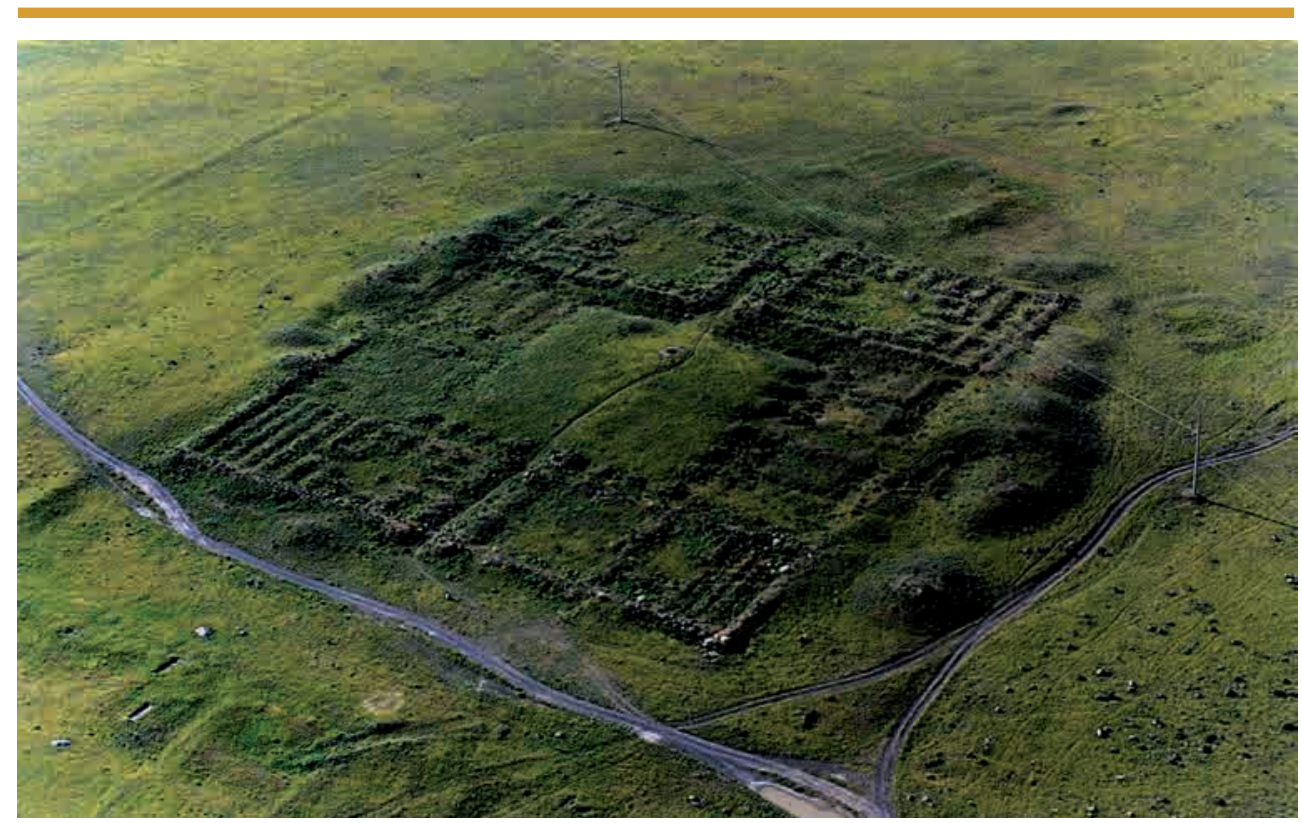

Рис. 3. Акыртас. Двореи. Аэрофото. Фото автора

Fig. 3. Akyrtas. Palace. Aero photo. Author's photo

и Каср аль-Джисс - здание, в котором исследователи не без основания видят подражание известному «дому правления» в Мерве [Brentjes, 1993, p. 6-7]. Огражденное стенами прямоугольное пространство во всех случаях заключает в себе замкнутые группы помещений с внутренними двориками, окружающими общий центральный двор (дворово-айванный центр в Охейдире). С мнением Б. Брентьеса солидарен авторитетный историк архитектуры С.Г. Хмельницкий [1992, c. 214-216].

Следовательно,

считают

Б. Брентьес и С.Г. Хмельницкий, Акыртас был построен по западноисламскому образцу. Это подтверждается техникой каменной кладки, имеющей несомненное средиземноморское происхождение. Известно, что ранняя исламская архитектура времени Омейядов черпала свои формы и приемы главным образом из греко-римского наследия. Этим определяется и время постройки - VIII в., время завоевания арабами Средней Азии и Казахстана.
Кутейба ибн Муслим, назначенный в 704 г., был наместником Хорасана и Мавераннахра. Его походы были направлены на восток и северо-восток - на Фергану и Чач, ставший в 714 г. его резиденцией. Отсюда Кутейба двинулся на тюркские города Испиджаб и Тараз. В 715 г. Кутейба был убит по приказу халифа Сулеймана, который подозревал его в сепаратизме. Действительно, есть основания думать, что честолюбивый полководец стремился к независимости от Багдада, и с этой целью переносил свои резиденции на восток. Такой постройкой, не законченной из-за гибели Кутейбы, и было строительство Акыртаса, которое велось в 714-715 гг. Здесь, в максимальной удаленности от Дамаска, он собирался править и отсюда, из стратегически удобного пункта, продолжать походы на восток.

Если это так, пишет С.Г. Хмельницкий, Акыртас - древнейший сохранившийся образец исламской архитектуры в Казахстане и Средней Азии, свидетель ее исламизации. 
Этим, видимо, и объясняется сочетание в нем черт сирийско-иракской архитектуры [Хмельницкий, 1992, c. 215].

Результаты исследований, которые, как было отмечено выше, проводились в 1996, 1998, 2004-2009 гг., позволяют высказать ряд новых гипотез и привести конкретные факты. Акыртас представляет собой монументальное сооружение, четырехугольное в плане, стены которого, выложенные из массивных каменных блоков красного песчаника, были возведены на высоту от 1 до 3-3,5 м. Блоки положены в один, два, реже в три-шесть рядов на северной крепостной стене и северо-западной башне. План постройки ориентирован длинными сторонами с севера на юг.

Главная улица соединяет северный и южный входы. Перпендикулярно ей с востока на запад проходит еще одна улица, упираясь в глубокие айваны. Улицы делят постройку на четыре части, из которых три состоят из помещений, расположенных вокруг дворов, а одна (северо-западная)

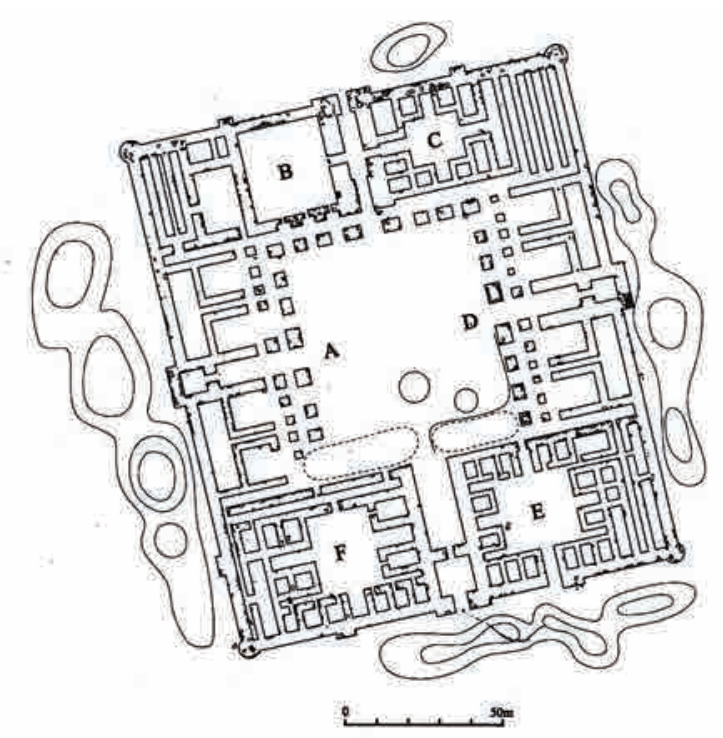

Рис. 4. Акыртас. План дворича (А. Нортхедж)

Fig. 4. Akyrtas. Plan of the Palace (A. Northjedge)
- свободна от застройки. Центр всей постройки занимает двор, по периметру которого поставлены каменные базы колонн размерами $5 \times 5$ м. В южной части двора прослеживаются котлованы двух водоемов - хаузов.

Краткая характеристика четыpex частей постройки.

Первая часть состоит из незастроенного квадратного участка размерами $27 \times 27$ м и группы помещений, выходящих во дворик размерами $13 \times 18$ м. Из них три представляют собой длинные коридорообразные помещения шириной 2,5 м и длиной $18 \mathrm{M}$.

Вторая часть также состоит из двух - жилой, включающей в себя 12 помещений и три айвана, группирующихся вокруг двора размерами $18 \times 18$ м, и второй - хозяйственной, где было устроено пять узких длинных помещений шириной от 2 до 3 м, выходящих во внутренний двор.

Третья часть включает 13 помещений, сгруппированных вокруг двора, который имеет самостоятельный выход наружу.

И, наконец, четвертая состоит из жилой части, располагающейся вокруг двора размерами $25 \times 34$ м. В ней насчитывается 18 жилых комнат, два айвана и три узких помещения, из которых одно - «П»-образное. Эта часть также имеет самостоятельный выход наружу. Стены сложены из блоков разных размеров. Некоторые из них имеют тщательно обработанные гладкие наружные плоскости, другие еще должны были пройти обработку. Размеры блоков различные: $115 \times 60 \times 60 \mathrm{~cm}$, $100 \times 50 \times 50 \mathrm{~cm}, 50 \times 50 \times 50 \mathrm{~cm}$, $60 \times 60 \times 50$ см с вариантами внутри этих размеров. 
Интересна техника кладки стен: они состоят из футляра, который образуют блоки, а внутри между ними заполнение из щебня и глины. Толщина стен колеблется от 5 м у внешних до 3,3-3,5 м внутренних.

Стены дворца были выложены из обработанных блоков красного песчаника на высоту 1-1,3 м. Блоки на угловых башнях были изготовлены не прямоугольными, а закругленными в сечении. При необходимости глыбы красного песчаника выполнялись трапециевидной или треугольной формы со скругленными углами. Блоки наружных стен были уложены в 3-4 ряда.

Планировка недостроенной постройки хорошо читается. Это было сооружение прямоугольное в плане, длинными сторонами расположенное по оси север-юг с небольшой сдвижкой. Размеры его 169×145 м. В центре находился перистильный двор размерами $89 \times 82$ м. По периметру двора, кроме южной стороны, планировалось устройство колонн для арочных перекрытий. В настоящее время в перистильном дворе находятся лишь массивные каменные базы под колонны размерами $5 \times 5$ м. Южную часть двора замыкают два продолговатых водоема - хауза.

Всю территорию дворца с севера на юг и с запада на восток пересекают две взаимно перпендикулярные улицы. Улица с севера на юг сквозная и выходит на придворцовую территорию. Улочка с запада на восток тупиковая и упирается в глубокие айваны. Пересекающиеся улицы делят территорию дворца на четыре больших части. Таким образом, планировка комплекса многодворная. Во всех угловых частях дворца внутренние дворики занимают центральное положение и окружены со всех сторон группами помещений. И только северо-западная угловая часть дворца свободна от застройки. Данная постройка имела в южной стене три тамбурных прохода в перистильный двор. Раскопки показали, что северная стена также имеет три тамбурных прохода наружу.

Северо-западная башня. Сохранившаяся высота башни равна шести рядам каменных блоков. Швы заложены мелкими плоскими обколотыми камнями красного песчаника и тщательно заделаны раствором ганча белого цвета, хорошего качества. Горизонтальные швы между рядами примерно 10-15 см, вертикальные шириной 5-7 см. Первый ряд каменной кладки уложен вертикальными рядами вплотную друг к другу и поставлен прямо на материк. Каменная кладка выведена под землю на глубину 3,1 м от уровня дневной поверхности. Башня книзу расширяется диаметром до 8,5 м, угол наклона приблизительно $25^{\circ}$ от вертикали. Блоки, образующие наружную поверхность башни, выведены по толщине в один ряд и выпилены, как уже отмечалось, полукруглыми в сечении.

Возникает естественный вопрос: была ли башня полая внутри либо она была забутована камнем? При такой большой площади башни - элемента дворца, логичным было бы предположить наличие внутрибашенного помещения. Для проверки версии по верху конструкции были заложены три шурфа, все они показали наличие забутовки внутри башни.

Расчищен и изучен парадный въезд во дворец, который находился в середине северной оборонительной стены. Он выделен прямоугольными пилонами, наличием гнезд в кладке блоков для установки, видимо, деревянного порога, а также наличием фигурных каменных блоков. Западный пилон разобран. Восточный пилон находится в хорошей сохранности.

Выяснилось, что нижний ряд каменных блоков является фундаментом под пилон. На нем выводился с отступом в несколько сантиметров 


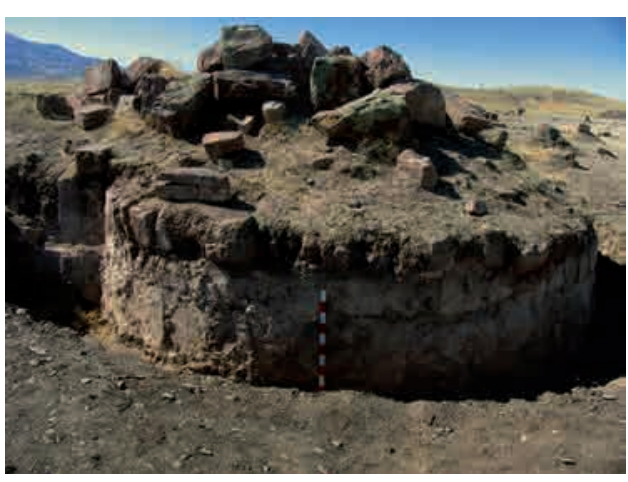

Рис. 5. Акыртас. Угловая башня до раскопок. Фото автора

Fig. 5. Akyrtas. Corner tower before the excavation. Author's photo

от наружной грани непосредственно сам пилон с уступами и фигурными блоками.

Проводилась зачистка северозападного блока, который состоит из двух частей. Первая, ближняя к улице, имеет размеры $27 \times 27$ м. В нее вел вход с центральной улицы и со стороны айвана - галереи. Здесь в стене были устроены три узких тамбуровидных входа. В середине западной стены этого большого помещения расчищена ниша на всю поднятую высоту стены, толщиной 1 м.

На поверхности помещения обнаружено несколько блоков. Все это позволяет предположить, что это большое помещение предназначалось для устройства в нем мечети. Блоки, часть из которых лежат на месте, а другие явно вывезенные отсюда, возможно служили базами колонн, которые поддерживали плоскую кровлю. Видимо, мечеть должна была быть столпной (лес колонн).

Именно такие мечети обозначены при раскопках города Кедера (городища Куйрыктобе) в Отрарском оазисе [Байпаков, 2005, с. 74, 129] и на городище Орнек, отождествленного с городом Куль-Шуб и названным в дорожниках Кудамы и Ибн-Хардадбека [Байпаков, 2013, с. 47, рис. 20]. Таким образом, есть достаточно доказательств тому, что Акыртас является

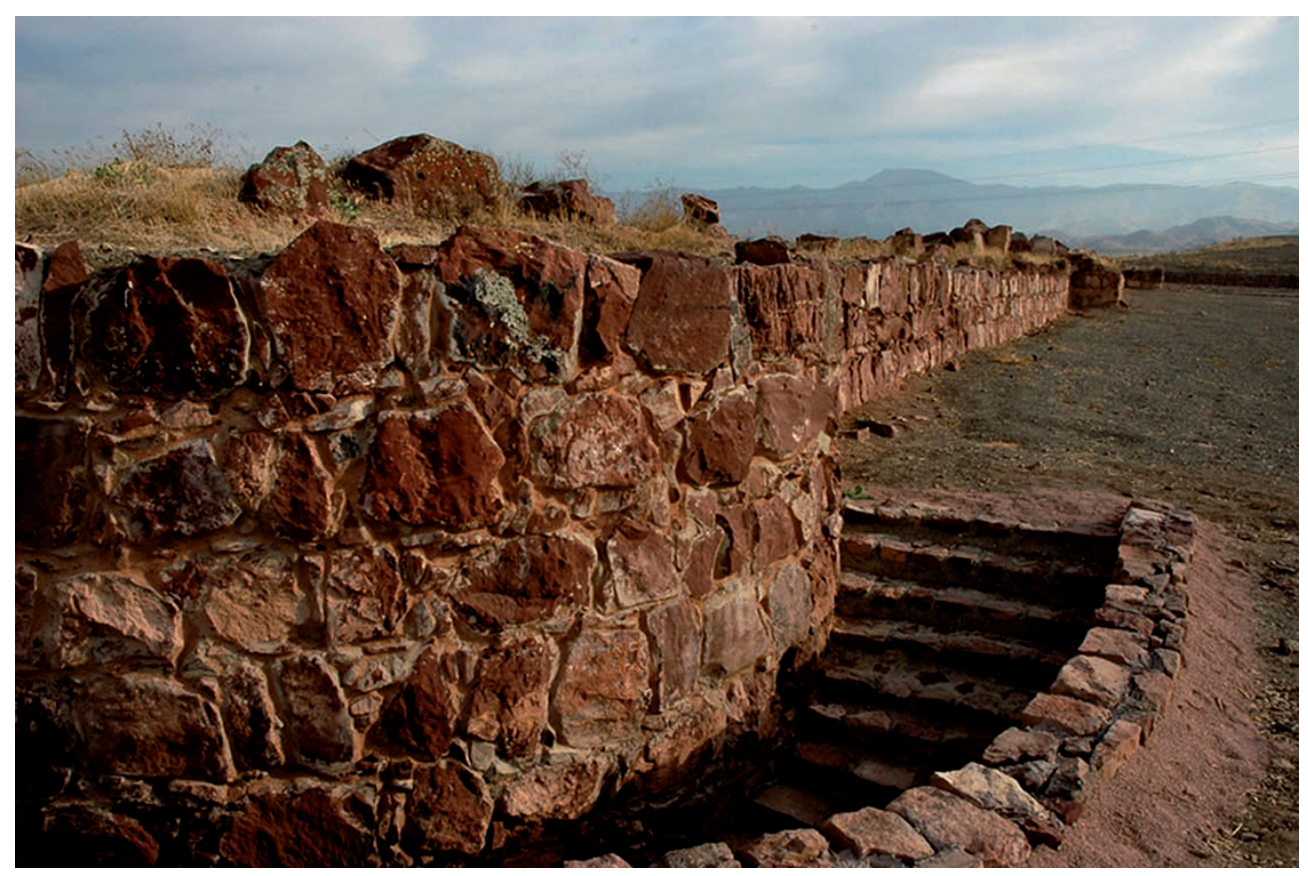

Рис. 6. Угловая башня после раскопок и реставрации. Фото автора

Fig. 6. Corner tower after excavation and restoration. Author's photo 
дворцом, и, по нашему мнению, он строился позднее, чем предполагает С.Г. Хмельницкий и, следовательно, строился не Кутейбой.

Если обратиться к событиям VII-VIII вв., связанных с завоеваниями арабами Средней Азии и Казахстана, то следует отметить, что после взятия Тараза в Жетысу, их продвижения до Кулана и Мирки сложилась обстановка, которая беспокоила Китайскую империю, намеревавшуюся подчинить все Жетысу и Среднюю Азию. Противостояния арабов и китайцев привело к их военному столкновению. Оно произошло на Таласе вблизи города Атлах в 751 г. В ходе Атлахской битвы победу одержали арабы, к которым присоединились карлуки.

В 766 г. в управление карлукского джабгу перешло все Жетысу с городами на Великом Шелковом пути с двумя ставками в Таразе и Суябе. Арабо-персидские источники среди городов Карлуков называют Нижний Барсхан, Касрибас, Куль-Шуб, ДжульШуб, Мирки, Нускет, Харай-Джуван, Тальхир [Волин, 1960, с. 73, 74, 76-77; Материалы..., 1973, с. 42-43; История Казахстана, 1996, с. 305-314].

Следует отметить, что именно карлуки одними из первых приняли ислам [Бартольд, 1963, с. 268]. Установление тесных связей карлуков и арабов, возможно, привело к тому, что по просьбе карлукского кагана арабы начали строительство для него летней резиденции в предгорьях Кыргызского Алатау. Такие случаи в истории взаимоотношений имеются. Так, по просьбе кагана Хазарского каганата в Византии построили для хазар в первой половине IX в. крепость Саркел [Артамонов, 1958].

Известно, что посол Волжской Булгарии, прибывший в 921 г. в Багдад, передал письмо своего царя халифу ал-Муктадиру. В письме «царь» просил халифа «прислать ему кого- либо, кто наставил его в вере, преподал бы ему законы ислама, построил бы для него мечеть, воздвиг бы для него кафедру», просит его также о постройке крепости, чтобы «укрепиться в ней от царей своих противников» и согласие было получено [Ковалевский, 1956, с. 13, 121].

Следует поддержать точку зрения о тождестве Акыртаса с городом на Великом Шелковом пути Касрибасом [Байпаков, 2013, с. 47]. Интересна этимология названия Касрибас. Первая часть его - слово «дворец» поарабски, которое является синонимом термина «айван». Это помещение, открытое со стороны внутреннего двора, кровля которого опирается на колонны. Именно такими были приемные залы во дворцах древней Парфии, Сасанидского Ирана, в средневековых дворцах арабского востока.

Основные функциональнопланировочные элементы традиционного исламского дворца включали: летние помещения с бассейном, фонтаном, расположенные на северной стороне; зимние помещения, расположенные с южной стороны; открытый внутренний двор - атриум; айваны, коридоры. Помещения имели высокие потолки.

В омейядских дворцах формировались три зоны: саламалак - это «мужская» зона - место приема гостей; харалан (гаремлан) - женская часть со спальными помещениями, кухней, комнатами для рукоделия; хадамлак - зона с производственными и жилыми помещениями для обслуживающего персонала и охраны. Дворцы возводились на обособленной территории, вдали от городов и других населенных мест, одновременно выполняя функции крепостей.

Структурным планировочным ядром дворца всегда служил «сахн» - открытый внутренний двор атриумного типа. Практически все помещения были ориентированы на двор. 
Стена была границей между внешней средой и внутренним пространством дворца. Она укреплялась башнями многоцелевого назначения: оборонительного, наблюдательного, а также для длительного хранения провизии в нишах внутренних стен. Микроклимат здесь образовывал восходящие потоки прохладного воздуха из-под земли. Дворцы были одно- и двухэтажными [Мухамед Забен Хамед Халид, 2001, с. 198].

Первый дворец арабоисламского мира был возведен в Дамаске (660-661 гг.). Он был построен на месте старого дворца из обработанного камня по приказу халифа Муавия. Второй был построен сыном Муавия - халифом и там строились дворцы в течение VII-XIII вв. Всего было построено 19 дворцов, положивших начало мусульманской дворцовой архитектуре. Среди этих дворцов наиболее совершенными были Каср аль Хайр ал-Гарби (727), Хайр аль-Шарки (727-729) [Мухамед Забен Хамед Халид, 2001, с. 202]. Если сравнить планировку двух этих дворцов, наиболее близок к Акыртасу дворец аль-Хайр аль-Шарки. Интересны интерьеры дворцовых помещений. Великолепно наружное оформление въездов, парапетов, стен, аркат. Поражает своей красотой дворец Хирбеталь-Мфаджар аль Мшатта [Мухамед Забен Хамед Халид, 2001, с. 202, рис. 4].

Следует также сопоставить изолированные узкие и длинные коридорообразные в плане помещения, которые присутствуют в застройке северо-восточного блока - их пять и в северо-западном - их два. Такие же узкие длинные помещения отмечены в застройке комплекса дворца альДжафари [Northedge, 1993, fig. 17]. К сожалению, сооружение Акыртас недостроенное, оно никогда не фунцинировало, не было обжито хотя бы частично. Ни в раскопках, ни вокруг на поверхности почти нет подъемного материала, который бы позволил обосновать точную дату строительства.

Есть разные точки зрения по поводу хронологии памятника. Мы имеем конкретную вероятную верхнюю дату, опираясь на сообщение Чань-Чуня. В начале XIII в. Акыртас уже был памятником, о нем уже никто не мог ничего конкретно объяснить даосскому монаху: ни жители ближайших Тараза и Сайрама, ни сопровождавшие его монголы, которые наверняка общались с местным населением.

Конкретную дату, которая вытекает из его же определения характера постройки как дворца, во многом аналогичному дворцам арабского мира, дает С.Г. Хмельницкий, связывая его с Кутейбой, который мог в 714-715 гг. начать строить себе и своей семье резиденцию.

По мнению П.И. Лерха и B.В. Бартольда, постройку следует относить к недостроенному буддийскому или несторианскому монастырю. Они ссылались на выбитые рисунки, в частности, рыбы на одном из каменных блоков. Наиболее правдоподобно звучит объяснение Акыртаса как караван-сарая, но тогда можно было бы ожидать сообщение о таком сооружении в арабских и персидских письменных источниках, но их нет. Г.И. Пацевич считает, что эта постройка скорее всего задумана как несторианский монастрь, оперируя тем, что в соседнем Таразе в раннем средневековье проживали христиане и была христианская церковь (несторианская). Строилась она в период до IX в.

Архитектор Т. Басенов определяет Акыртас как дворец-замок и датирует его VII-VIII вв. [Маргулан, Басенов, Мендикулов, 1959, с. 94-96]. A.Н. Бернштам датировал постройку XII-XIV вв. и, определив ее как незаконченное сооружение сирийско- 
византийских строителей, находил, что каменные кладки похожи на те, что использовались при строительстве стен городов Крыма. Саму же постройку он связывал с несторианами. Датировку он дал на основании раскопанных мусульманских захоронений. Следовательно, сооружение Акыртас (Юго-Западное Жетысу) является выдающейся постройкой арабской архитектуры. Она появилась здесь благодаря политическим, культурным и религиозным связям Карлукского каганата и Арабского ха- лифата - древнетюркского и арабского миров.

Заключение. Акыртас все еще остается загадочным монументальным сооружением из камня на территории Казахстана. Сделать выводы о назначении постройки, времени ее сооружения позволят лишь полномасштабные раскопки самой постройки из камня и всех сооружений, входящих в инфраструктуру этого архитектурно-археологического комплекса.

\section{ЛИТЕРАТУРА}

1. Акишев А.К. «Сиюйцзи» - «Записки о западном крае» даосского учителя Чань Чуня // Тамыр. 2004. № 12 (апрель-июнь). С. 52-71.

2. Артамонов М.И. Саркел - Белая Вежа // МИА. Труды Волго-Донской археологической экспедиции. М.-Л.: «Наука», 1958. № 62. С. 7-84.

3. Байпаков К.M. Городище Куйрыктобе - город Кедер. Алматы: «Баур», 2005. 183 c.

4. Байпаков К.M. Древняя и средневековая урбанизация Казахстана (по материалам исследований ЮККАЭ). Алматы: Институт археологии им. А.Х. Маргулана, 2012. Кн. I: Урбанизация Казахстана в эпоху бронзы - раннем средневековье. 390 с., ил.

5. Байпаков К.М. Древняя и средневековая археология Казахстана. Алматы: Институт археологии им. А.Х. Маргулана, 2013. Кн. II: Урбанизация Казахстана в IX - начале XIII в. 516 с.

6. Бартольд В.В. Очерк истории Семиречья // Соч. М.: «Наука», 1963. Т. II, ч. 1. C. 23-108.

7. Бартольд В.В. О христианстве в Туркестане в домонгольский период (По поводу Семиреченских надписей) // Соч. М.: «Наука», 1964. Т. ІІ, ч. 2. С. 265-302.

9. Бартольд В.В. Отчет о командировке в Среднюю Азию с научной целью // Соч. М.: «Наука», 1966. T. IV. С. 21-91.

10. Басенов T.К. О сооружении Тас-Акыр // Известия Академии наук КазССР. Серия архитектурная. 1950. Вып. 2. С. 83-89.

11. Бернштам А.Н. Таласская долина (1936-1938 гг.) // ТСАЭ. Материалы и исследования по археологии Казахской ССР. Алма-Ата, 1949. Т. І. (1936-1938 гг.).

12. Волин C. Сведения арабских источников IX-XVI вв. о долине реки Талас и смежных районах // Новые материалы по древней и средневековой истории Казахстана. ТИИАЭ АН КазССР. 1960. Т. 8. С. 72-92.

13. Иванов Л.Д. К вопросу о некоторых туркестанских древностях // Известия Русского географического общества. 1886. Т. 21. С. 162-167.

14. Ивлев Н. Зов Акыртаса // Памятники истории, культуры Казахстана: сб. научн. ст. Алма-Ата: Цент. совет Казахского об-ва охраны памятников, истории и культуры, 1989. Вып. 4. С. 91-93.

15. История Казахстана: с древнейших времен до наших дней. В 5-ти томах. Гл. ред. М.К. Козыбаев. Алматы: «Атамура», 1996. Т. 1: Казахстан от эпохи палеолита до позднего средневековья. 540 с., ил.: табл.

16. Каллаур B.А. Акыр-Тас // ПТКЛА. Ташкент, 1896. С. 25-27. 
17. Каллаур В.А. Древние местности Аулиеатинского уезда на старом караванном пути из Тараза (Таласа) в Восточный Туркестан // ПТКЛА. Год первый. Ташкент, 1897. C. $1-9$.

18. Каллаур В.А. Поездка на Ахир-Тас (Ахур-Таш, Таш-Ахир) // ПТКЛА. Ташкент, 1905. С. 29-36.

19. Ковалевский А.П. Посольство Багдадского халифа к царю Волжских Булгар в 921-922 годах // Ковалевский А.П. Книга Ахмеда ибн-Фадлана о его путешествии на Волгу. Харьков: Изд-во Харьковского госуниверситета им. А.М. Горького, 1956. 345 c.

20. Лерх П.И. Археологическая поездка в Туркестанский край в 1867 г. СПб.: Тип. Имп. АН, 1870.40 с.

21. Маньковская Л.Ю. Типологические основы зодчества Средней Азии (IX начало XX в.). Ташкент: «Фан», 1980. 183 с.: ил.

22. Маргулан А., Басенов T., Мендикулов М. Архитектура Казахстана. Алма-Ата: Каз. гос. изд-во, 1959. 171 с.: табл. ч. $2.280 \mathrm{c}$.

23. Материалы по истории киргизов и Киргизии. М.: «Наука», 1973. Вып. I,

24. Мухамед Забен Хамед Халид. Об истории возникновения дворцовой архитектуры арабо-исламского мира // Известия НАН РК. Сер. обществ. наук. 2000. № 1. C. 196-208. C. $80-85$.

25. Пачевич Г.И. Ахыр-Таш // Вестник Академии наук КазССР. 1949. № 4.

25. Хмельниикий С.Г. Между арабами и тюрками. Архитектура Средней Азии IX-X веков». Берлин-Рига: «Continent Ltd», 1992. 343 с.

20. Шарденова 3.Ж. Крепость средневекового Касрибаса // Известия НАН РК. Cер. обществ. наук. 2010. № 1. C. 194-201.

21. Baipakov K. Silk Road serial transamination Achievements and perspectives // Silk Road. Arts and Humanities of the Silk Road. Keimyung University, 2016. Vol. II. P. 171-180.

22. Brentjes B. Islamic art and architecture in Central Asia // Journal of Central Asia. 1993. Vol. XVI, 1-2. P. 1-239.

23. Northedge A. An interpretation of the palace of the Caliph at Samarra (Dar alKhilafa or Jawsaq al-Khaqani) // Arts orient’s. 1993. № 27. P. 143-170.

\section{Седения об авторе:}

Байпаков Карл Молдахметович - доктор исторических наук, профессор, академик НАН РК, директор Государственного музея «Центр сближения культур» (г. Алматы, Казахстан); kbaipakov@mail.ru

\section{АҚЫРТАС АРХИТЕКТУРАЛЫҚ АРХЕОЛОГИЯЛЫҚ КЕШЕНІ}

\section{К.М. Байпақов}

Ақыртас темірлі құмды тас блоктардан салынып бітпеген құрылыс. Ескерткіш аумағынан екі көше жақсы көрінеді: бірі солтүстіктен-оңтүстікке тіке өтіп кететін, ал екіншісі шығыстан батысқа қарай тұйықталған, жабық айванға тіреледі. Ақыртас кешені жөнінде әртүрлі пікірлер бар: будда немесе несториандық ғибадатхана, керуен-сарай немесе резиденциялық сарай ретінде салынған. Жобалаудың баламасы, құрылыс техникасының сипаты бойынша кейбір зерттеушілер Ақыртасты 8 ғ. араб сәулетшілері салған сарай деп есептейді. Автордың алған археологиялық материалдары құрылыстың басталу мерзімін 751 жыл Атлах шайқасынан кейінгі уақыт деп мерзімдеуге мүмкіндік береді.

Түйін сөздер: археология, Ұлы Жібек жолы, Ақыртас, Касрибас, қарлұқтар, арабтар, Араб Халифаты, Кутейба, Атлах шайқасы, сарай, тас блоктар, тас алатын карьер 
Байпаков К.M. Архитектурно-археологический комплекс Акыртас

\section{ARCHITECTURAL-ARCHAEOLOGICAL COMPLEX AKYRTAS}

\section{K.M. Baipakov}

Akyrtas is unfinished structure of stone blocks of ferruginous sandstone. On the territory of the monument two streets are well read: one of them, in the north-south direction, is through, the other, in the east-west direction, is dead-ended, it strikes against iwans that have no passages. Concerning the Akyrtas complex there are different opinions: it was built as a Buddhist or Nestorian monastery, caravanserai or palace-residence. By analogy with the layout, nature of construction equipment, some researchers believe the Akyrtas a palace, built by Arab architects in the VIII century. Archaeological materials obtained by the author allow dating the beginning of the construction to the time after the Battle of Artlakh in 751 year.

Keywords: archaeology, Great Silk Road, Akyrtas, Kasribas, Karluks, Arabs, Arab Caliphate, Kuteiba, the Battle of Artlakh, palace, stone blocks, quarry of stone mining

\section{REFERENCES}

1. Akishev, A. K. 2004. In Tamyr, 12, 52-71 (in Russian).

2. Artamonov, M. I. 1958. In MIA. Trudy Volgo-Donskoy arheologicheskoy ekspeditsii (Materials and research on the archaeology of the USSR. Proceedings of the Volga-Don archaeological expedition). Moscow-Leningrad: «Nauka» Publ., 62, 7-84 (in Russian).

3. Baipakov, K. M. 2005. Gorodische Kuyryiktobe - gorod Keder (Kuiryktobe settlement - the city of Keder). Almaty: «Baur» Publ. (in Russian).

4. Baipakov, K. M. 2012. Drevnyaya i srednevekovaya urbanizatsiya Kazahstana (po materialam issledovaniy Yuzhno-Kazahstanskoy kompleksnoy arheologicheskoy ekspeditsii). Kn. I: Urbanizatsiya Kazahstana v epohu bronzyi - rannem srednevekove (Ancient and medieval urbanization of Kazakhstan (based on research materials of the South Kazakhstan complex archaeological expedition). Book. I: Urbanization of Kazakhstan in the Bronze Age - the early Middle Ages). Almaty (in Russian).

5. Baipakov, K. M. 2013. Drevnyaya i srednevekovaya arheologiya Kazahstana. Kn. II. Urbanizatsiya Kazahstana v IX-nachale XIII vv. (Ancient and medieval archeology of Kazakhstan. Book II. Urbanization of Kazakhstan in the 9th - early 13th centuries). Almaty (in Russian).

6. Bartold, V. V. 1963. In Sochineniya (Collected works). Moscow: «Nauka» Publ., т. II, part 1, 23-108 (in Russian).

7. Bartold, V. V. 1964. In Sochineniya (Collected works). Moscow: «Nauka» Publ., т. II, part 2, 265-302 (in Russian).

9. Bartold, V. V. 1966. In Sochineniya (Collected works). Moscow: «Nauka» Publ., IV, 21-91 (in Russian).

10. Basenov, T. K. 1950. In Izvestiya Akademii nauk KazSSR. Seriya arhitekturnaya (News of the Academy of Sciences of the Kazakh SSR. Architectural Series), 2, 83-89 (in Russian).

11. Bernshtam, A. N. 1949. In TSAE. Materialy i issledovaniya po arheologii Kazahskoi SSR (Proceedings Semirechensk archaeological expedition. Materials and research on the archeology of the Kazakh SSR), I. Alma-Ata (in Russian).

12. Volin, S. 1960. In Novyie materialyi po drevney i srednevekovoy istorii Kazahstana. Trudy IIAE AN KazSSR (New materials on the ancient and medieval history of Kazakhstan. Proceedings of the Institute of History, Archeology and Ethnography of the Academy of Sciences of the Kazakh SSR), 8, $72-92$ (in Russian).

13. Ivanov, L. D. 1886. In Izvestiya RGO (Proceedings of the Russian Geographical Society), 21, 162-167.

14. Ivlev, N. 1989. In Pamyatniki istorii, kultury Kazahstana (Monuments of history, culture of Kazakhstan), 4, 91-93 (in Russian). 
15. Istoriya Kazahstana (History of Kazakhstan), 1. 1996. Kozybayev, M. K. (Ed.). Almaty: «Atamura» (in Russian).

16. Kallaur, V. A. 1896. In PTKLA (Protocols of the Turkestan circle of archeology lovers). Tashkent, 25-27 (in Russian).

17. Kallaur, V. A. 1897. In PTKLA (Protocols of the Turkestan circle of archeology lovers). Tashkent, 1-9 (in Russian).

18. Kallaur, V. A. 1905. In PTKLA (Protocols of the Turkestan circle of archeology lovers). Tashkent, 29-36.

19. Kovalevskiy, A. P. 1956. Kniga Ahmeda ibn-Fadlana o ego puteshestvii na Volgu (Book of Ahmed Ibn Fadlan about his journey to the Volga). Harkov (in Russian).

20. Lerh, P. I. 1870. Arheologicheskaya poezdka v Turkestanskiy kray v $1867 \mathrm{~g}$. (Archaeological trip to Turkestan in 1867). Saint Petersburg (in Russian).

21. Mankovskaya, L. Yu. 1980. Tipologicheskie osnovyi zodchestva Sredney Azii (IX nachalo XX v.) (Typological foundations of the architecture of Central Asia (IX beginning of $X X$ centuries)). Tashkent: "Fan" Publ. (in Russian).

22. Margulan, A., Basenov, T., Mendikulov, M. 1959. Arhitektura Kazahstana (Architecture of Kazakhstan). Alma-Ata: Kaz. gos. izd-vo (in Russian).

23. Materialy po istorii kirgizov i Kirgizii (Materials on the history of Kirghiz and Kirghizia). 1973. Issue I, part 2 (in Russian).

24. Muhamed Zaben Hamed Halid. 2000. In Izvestiya NAN RK. Seriya obschestv. nauk (News of the National Academy of Sciences of the Republic of Kazakhstan. Social Sciences Series), 1, 196-208 (in Russian).

25. Patsevich, G. I. 1949. In Vestnik Akademii nauk KazSSR (Bulletin of the Academy of Sciences of the Kazakh SSR), 4, 80-85 (in Russian).

26. Hmelnitskiy, S. G. 1992. Mezhdu arabami i tyurkami (Arhitektura Sredney Azii $I X-X$ vekov (Between the Arabs and the Turks. Architecture of Middle Asia IX-X centuries). Berlin-Riga, «Continent Ltd» (in Russian).

27. Shardenova, Z. Zh. 2010. In Izvestiya NAN RK. Seriya obschestv. nauk (News of the National Academy of Sciences of the Republic of Kazakhstan. Social Sciences Series), 1, 194-201 (in Russian).

28. Baipakov, K. 2016. In Silk Road. Arts and Humanities of the Silk Road. Keimyung University. Vol. II, 171-180 (in English).

29. Brentjes, B. 1993. In Journal of Central Asia. Vol. XVI, 1-2, 1-239 (in English). 30. Northedge, A. 1993. In Arts orient's, 27, 143-170 (in English).

\section{About the Author:}

Baipakov Karl M. Doctor of Historical Sciences, Professor, Academician of the National Academy of Sciences of Kazakhstan, Director of the State Museum «Center for the Rapprochement of Cultures», Almaty, Kazakhstan; kbaipakov@mail.ru

\footnotetext{
Мүдделер қақтығысы туралы ақпаратты ашу. Автор мүдделер қақтығысының жоқтығын мәлімдейді. / Раскрытие информации о конфликте интересов. Автор заявляет об отсутствии конфликта интересов. / Disclosure of conflict of interest information. The author claims no conflict of interest.

Мақала туралы ақпарат / Информация о статье / Information about the article.

Редакцияға түсті / Поступила в редакцию / Entered the editorial office: 15.10.2018.

Рецензенттер мақұлдаған / Одобрено рецензентами / Approved by reviewers: 22.10.2018.

Жариялауға қабылданды / Принята к публикации / Accepted for publication: 25.10.2018.
} 